\title{
On the justification and possibilities of soft paternalism
}

Thesis 1: Even employing soft incentives like 'nudges' which - at least in principle - do not impair the affected individuals' freedom to decide, soft (or libertarian) paternalism faces the same problem any other kind of paternalism does: What justifies government interventions in individuals' decisions if no third parties' interests are involved? The only possibility for such a justification available so far is the idea of collective self-binding as proposed by G. Brennan and L. Lomasky (1983).

Political interventions into market processes are usually justified by the existence of external effects and/or public goods. Here, rights and interests of third parties are crucial. The goal is to compensate positive as well as negative effects of (legitimate) individual actions on uninvolved third parties. In contrast to this, the rights and interests of third parties are not at the core of paternalistic measures. Their objective is to help citizens make decisions that are in their own best interest.

To influence individuals contrary to their own preferences is - at least at first glance - in conflict with the traditional vision of normative individualism. According to this concept, it is the values of autonomous individuals alone that ought to be relevant in society, and nobody has the right to prescribe to others which values to accept. This concept also underlies (traditional) normative economics, i.e. welfare economics, and it is rendered concrete in the concept of consumer sovereignty. However, paternalism does not have to be seen in contradiction to this normative concept as soon as, following the philosophical tradition, we accept that humans are able to reflect their own behaviour. This implies that they possess hierarchically ordered preference functions; they are capable of evaluating their short-term preferences with their superordinated reflexive (long-term) preferences. Paternalistic political measures can be understood as collective self-bindings via the political process. Even if it is impossible to justify all paternalistic measures that are installed today, a general rejection of any instance of paternalism due to its incompatibility with liberal principles is no longer possible.

Thesis 2: In order to motivate individuals to extend their contributions to old age pensions, soft incentives can be effective and hardly lead to moral problems. Applying such incentives in health care, however, the picture is quite different. Measures proposed so far to fight obesity do not seem to lead to any moral problems, but are hardly effective. Measures to increase the readiness for organ donations might be very effective, but are afflicted with serious moral problems.

A whole series of policy measures have been proposed within the 'nudge' framework. They relate mainly to retirement provisions and to the health system; among the latter mainly problems of obesity, smoking, and organ donations are tackled. The measures proposed often present a specific alternative as status quo 
that a particular point of view evaluates as being preferable. There is no problem to deviate from this default solution, but it demands an active decision.

Even if their long-term are smaller than their short-term effects, measures relating to retirement provisions are feasible and appear to be effective. Moreover, it is difficult to pinpoint why they should create any moral problem. The situation is quite different, however, with respect to health care. The idea of T. O'Donoghue and $\mathrm{M}$. Rabin (2003) to reduce smoking is, for example, hardly feasible, and if introduced nevertheless, can lead to extremely severe paternalistic measures. The measures to fight obesity might be feasible and not lead to moral problems, but most of them are not very effective at all. A change in organ donation from the consent to the objection rule may considerably increase the number of organs available for transplants. However, this rule implies serious moral problems, because the extraction of an organ implies an invasion into the integrity of a human person, even if this person is already deceased. According to our (current) prevailing moral convictions, such an invasion - absent the consent of the person involved - should only be allowed under very restrictive conditions. Whether the fact that the life of another human person can be prolonged is sufficient for this is contested. Thus, soft paternalistic measures might not be as innocuous as may be perceived at a first glance.

Thesis 3: We cannot escape these problems by abstaining from all paternalistic measures and/or just maintaining the status quo. As soon as it is realised that the given status quo has an impact on the individuals' decisions and as far as the default option is subject to political decisions, one has to decide which default option to choose, and this choice has to be justified. Insofar, we are necessarily confronted with choosing default options and, therefore, with applying measures of (soft) paternalism. Their usage should of course be justified by democratic means.

Some (fundamentalist economic) critics of soft paternalism insinuate an (in their opinion) ideal world without any paternalism. Actually, however, we are living in a world in which paternalism is omnipresent. A radical anti-paternalism, as might be traced back to John Stuart Mill and as is proposed by some economists, would hardly make sense. Moreover, it is - presumably - impossible to become realised. This holds true for democratic political systems at least, and it becomes quite obvious in the Swiss democratic system, where many paternalistic measures are politically legitimised by referenda.

There moreover is another reason why radical anti-paternalism is hardly possible. As soon as it is realised that the way information is presented influences the individuals' decisions, the question how information should be presented needs to be answered. Whenever the default option has an impact, the government or the respective firm influences the citizens (or employees) by providing the 'normal' situation. The same holds true whenever behaviour depends on the frame used. In these situations, one should consider which frame should be chosen or which default option proposed. Closing one's eyes to this fact and just continuing what has been done before is hardly a rational strategy.

Critics of soft paternalism often state that there exists no omniscient actor who knows the true preferences of the individuals, which would be a precondition for 
responsible applications of soft paternalistic measures. Thus, it is often not taken into account that, in democratic systems, decisions about introducing such measures are not taken by a central planner, but (in the direct democratic system) by the citizens themselves or (in the representative system) by their representatives. If one accepts the democratic principle, the question is whether the citizens approve a policy and not whether it is compatible with a particular ideology. If a majority of citizens demands the introduction of mechanisms for collective self-binding, this cannot be prohibited in a democracy. In a democratic system, deciding which rules are to be followed is the task of the citizens themselves (or their representatives).

\section{References}

Brennan, G., and L. Lomasky (1983), Institutional Aspects of Merit Goods Analysis, Finanzarchiv N.F. 41, pp. $183-206$.

O'Donoghue, T., and M. Rabin (2006), Optimal Sin Taxes, Journal of Public Economics 90, pp. $1825-1849$.

*) (c) Gebhard Kirchgässner 